\title{
Preparation of Chiral Hydroxy Esters Using Actinobacteria: Biocatalyst Activity of Marine-Derived Micromonospora and Streptomyces Strains
}

\author{
Kohji Ishihara $^{1 *}$, Aiko Fujita ${ }^{1}$, Akane Sakiyama ${ }^{1}$, Yuko Kobayashi ${ }^{1}$, Kaoru Hori ${ }^{1}$, Kanako Maruike $^{1}$, \\ Noriyoshi Masuoka ${ }^{1}$, Nobuyoshi Nakajima ${ }^{2}$, Hiroki Hamada ${ }^{1}$ \\ ${ }^{1}$ Department of Life Science, Okayama University of Science, Okayama, Japan \\ ${ }^{2}$ Graduate School of Health and Welfare, Okayama Prefectural University, Soja, Japan \\ Email: *ishihara@dls.ous.ac.jp
}

Received November 28, 2012; revised December 29, 2012; accepted January 6, 2013

\begin{abstract}
To research the potential ability of marine-derived actinomycetes to act as biocatalysts, 8 Micromonospora strains and 5 Streptomyces strains were screened. Two recommended media (227 and 1076 media) and 2 modified media (1076-25\% and P-1076-25\% media) for liquid culture of these marine-derived actinomycetes were tested. As a result, 2 Micromonospora strains (Micromonospora sp. NBRC107096 and 107097) cultured with the 1076-25\% medium and 2 Streptomyces strains (Streptomyces tateyamensis NBRC105048 and Streptomyces sp. NBRC105896) cultured with P-1076-25\% medium showed a good growth. The stereoselective reduction of $\alpha$-keto esters using these 4 actinomycetes was tested. As a result, it was found that these strains had a reducing activity toward various $\alpha$-keto esters. The introduction of L-glutamate or sucrose as an additive remarkably increased the conversion ratios in the reduction of substrates by the Micromonospora strain. Furthermore, in the presence of L-alanine, Streptomyces tateyamensis NBRC105048 reduced ethyl pyruvate, ethyl 2-oxobutanoate, ethyl 2-oxopentanoate, ethyl 2-oxohexanoate, and ethyl 3 -methyl-2-oxobutyrate to the corresponding $\alpha$-hydroxy ester with a high conversion ratio and with excellent enantiomeric excess. Thus, we found that these marine-derived actinomycetes have great potential to be used as biocatalysts for stereoselec- tive reduction of carbonyl compounds.
\end{abstract}

Keywords: Marine Bacteria; Micromonospora; Streptomyces; Biocatalyst; Chiral Alcohol

\section{Introduction}

Actinobacteria comprise one of the largest taxonomic units among the 18 major lineages currently recognized within the domain Bacteria, which consists of 5 subclasses and 14 suborders [1,2]. Among the 5 subclasses, Actinobacteria (commonly called actinomycetes) are widely distributed in soil and are well known to produce secondary metabolites [3-6], notably antibiotics [7], antitumor agents [8], immunosuppressive agents [9] and industrially important enzymes [10]. Furthermore, actinomycetes also have a capacity for biotransformation; therefore, they are used as biocatalysts for the preparation of chiral alcohols from carbonyl compounds [11-14]. Thus, actinomycetes are medically, pharmacologically, and industrially useful.

Many actinomycetes have been isolated and screened from soil in the last few decades [15]. Recently, the rate of novel metabolites discovery from terrestrial actionmycetes has decreased significantly [16], therefore the

"Corresponding author. search for marine actinomycetes, including free-living and marine invertebrate-associated actinomycetes, has attracted attention as an alternative approach [17-20]. For example, it was found that strains of Salinispora - marine actinomycetes - produce useful bioactive compounds such as arenimycin and salinosporamide A [21,22]. Moreover, it has been reported that Salinispora strains reduce toward $\alpha$-keto esters and their derivatives stereoselectively [23]. Thus, new applications of marine actinomycetes are expected from the viewpoint of asymmetric syntheses of bioactive substances. However, the potential biocatalyst activity of other marine-derived actinomycetes has not been investigated.

This study describes the stereoselective reduction of $\alpha$-keto esters by marine-derived Micromonospora and Streptomyces strains as novel biocatalysts (Figure 1).

\section{Materials and Methods}

\subsection{Instruments and Chemicals}

Gas chromatography was performed using GL Science 


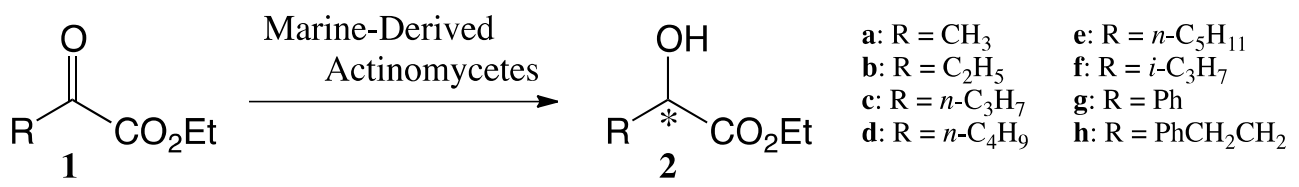

Figure 1. The reduction of $\alpha$-Keto esters (1a-h) by marine-derived actinomycetes.

GC-353 gas chromatographs (GL Science Inc., Tokyo, Japan) equipped with capillary columns (DB-Wax, Agilent Technologies, Santa Clara, CA, USA, $0.25 \mu \mathrm{m}$, $0.25 \mathrm{~mm} \times 30 \mathrm{~m}$; TC-1, GL Science Inc., $0.25 \mu \mathrm{m}, 0.25$ $\mathrm{mm} \times 30 \mathrm{~m}$; CP-Chirasil-DEX CB, Varian Inc., Lake Forest, CA, USA, $0.25 \mu \mathrm{m}, 0.25 \mathrm{~mm} \times 25 \mathrm{~m}$; Gamma DEX 225, Sigma-Aldrich Co., St. Louise, MO, USA, $0.25 \mu \mathrm{m}, 0.25 \mathrm{~mm} \times 30 \mathrm{~m}$ ). Ethyl pyruvate (Figure 1, 1a), diatomaceous earth (granular), polypepton, L-alanine, and Daigo's artificial seawater SP were purchased from Wako Pure Chemical Industries Ltd., Osaka, Japan. Difco $^{\mathrm{TM}}$ soluble starch and Bacto ${ }^{\mathrm{TM}}$ yeast extract were purchased from Becton, Dickinson and Co., Franklin Lakes, NJ, USA. Ethyl lactate (2a), ethyl 3-methyl2-oxobutyrate (1f), ethyl 2-oxo-4-phenylbutyrate (1h), ethyl 2-hydroxy-4-phenylbutyrate (2h), and beef extract were purchased from Sigma-Aldrich. Ethyl benzoylformate (1g) and ethyl mandelate (2g) were obtained from Tokyo Chemical Industry, Co. Ltd., Tokyo, Japan. Ethyl 2-oxobutanoate (1b), ethyl 2-oxopentanoate (1c), ethyl 2-oxohexanoate (1d), ethyl 2-oxoheptanoate (1e), and $\alpha$-hydroxy esters (2b-f) were prepared according to procedures in the literature [24].

\subsection{Microorganisms and Culture}

Micromonospora sp. NBRC107092, 107093, 107094, 107095, 107096, 107097, 107098, 107099 (from marine sponge), Streptomyces hygroscopicus subsp. Hygroscopicus NBRC100580 (from marine fish), Streptomyces marinus NBRC105047 (from marine sponge), Streptomyces tateyamensis NBRC105048 (from marine sponge), Streptomyces haliclonae NBRC105049 (from marine sponge), and Streptomyces sp. NBRC105896 (from marine sponge) were purchased from the National Institute of Technology and Evaluation, Biological Resource Center, Japan (NBRC). These marine-derived actinomycetes were each maintained in NBRC-recommended medium $(227,228,1076$, and 1077) solidified with $1.5 \%$ agar.

The 227 medium (ISP medium No. 2) comprised $4.0 \mathrm{~g}$ of Bacto $^{\mathrm{TM}}$ yeast extract, $10.0 \mathrm{~g}$ of Bacto ${ }^{\mathrm{TM}}$ malt extract, and $4.0 \mathrm{~g}$ of D-glucose per 1 liter of distilled water $(\mathrm{pH}$ 7.3). The 228 medium comprised $1.0 \mathrm{~g}$ of Bacto ${ }^{\mathrm{TM}}$ yeast extract, $1.0 \mathrm{~g}$ of beef extract, $2.0 \mathrm{~g}$ of NZ amine, type A, and $10.0 \mathrm{~g}$ of D-glucose per 1 liter of distilled water $(\mathrm{pH}$ 7.3). The 325 medium ( $75 \%$ marine water) is comprised of $10.0 \mathrm{~g}$ of polypepton, $2.0 \mathrm{~g}$ of Bacto ${ }^{\text {тм }}$ yeast extract, $0.5 \mathrm{~g}$ of $\mathrm{MgSO}_{4} \cdot 7 \mathrm{H}_{2} \mathrm{O}$, and $27.0 \mathrm{~g}$ of Daigo's artificial seawater SP per 1 liter of distilled water $(\mathrm{pH} 7.3)$. The 1076 medium (ISP No. 2, 50\% marine water) comprised $4.0 \mathrm{~g}$ of Bacto ${ }^{\mathrm{TM}}$ yeast extract, $10.0 \mathrm{~g}$ of Bacto ${ }^{\mathrm{TM}}$ malt extract, $4.0 \mathrm{~g}$ of D-glucose, and $18.0 \mathrm{~g}$ of Daigo's artificial seawater SP per 1 liter of distilled water $(\mathrm{pH} \mathrm{7.2)}$. The 1077 medium (50\% marine water) comprised $2.0 \mathrm{~g}$ of Bacto $^{\mathrm{TM}}$ yeast extract, $10.0 \mathrm{~g}$ of Difco ${ }^{\mathrm{TM}}$ soluble starch, and $18.0 \mathrm{~g}$ of Daigo's artificial seawater SP per 1 liter of distilled water ( $\mathrm{pH} 7.2$ ). The 1076-25\% medium (ISP No. $2,25 \%$ marine water) comprised $4.0 \mathrm{~g}$ of Bacto ${ }^{\text {TM }}$ yeast extract, $10.0 \mathrm{~g}$ of Bacto ${ }^{\mathrm{TM}}$ malt extract, $4.0 \mathrm{~g}$ of D-glucose, and $9.0 \mathrm{~g}$ Daigo's artificial seawater SP per 1 liter of distilled water ( $\mathrm{pH}$ 7.3). The P-1076-25\% medium comprised $10.0 \mathrm{~g}$ of polypepton, $4.0 \mathrm{~g}$ of Bacto ${ }^{\mathrm{TM}}$ yeast extract, $10.0 \mathrm{~g}$ of Bacto ${ }^{\mathrm{TM}}$ malt extract, $4.0 \mathrm{~g}$ of D-glucose, and $9.0 \mathrm{~g}$ of Daigo's artificial seawater SP per 1 liter of distilled water ( $\mathrm{pH} 7.3$ ).

Micromonospora strains were grown in 227, 1076, $1076-25 \%$, and $\mathrm{P}-1076-25 \%$ media $(500 \mathrm{~mL})$ for 3 days at $25^{\circ} \mathrm{C}$ with aerobic shaking in baffled 2-L flasks in the dark. The Streptomyces strains were grown in 325,1076 , $1076-25 \%$, and P-1076-25\% media (500 mL) for 5 days at $25^{\circ} \mathrm{C}$ with aerobic shaking in baffled 2-L flasks in the dark. The marine actinomycete cells were harvested by filtration on filter paper (Whatman, No. 4) in vacuo and washed with saline $(0.85 \% \mathrm{NaCl}$ aq. $)$.

\subsection{Mreduction of $\alpha$-Keto Esters with Marine Actinomycetes Whole Cells}

Saline-washed wet cells ( $0.5 \mathrm{~g}$, dry weight approximately $0.2 \mathrm{~g})$ were resuspended in a large test tube $(\phi 30 \mathrm{~mm} \times$ $200 \mathrm{~mm})$ containing $20 \mathrm{~mL}$ of saline. The substrate $(0.15$ mmol; corresponding substrate concentration was 7.5 $\mathrm{mM})$ and additive $(5.0 \mathrm{mmol})$ were added, and the reaction mixture was incubated aerobically (reciprocating shaking at $\left.120 \mathrm{~min}^{-1}\right)$ at $25^{\circ} \mathrm{C}$. A portion $(0.5 \mathrm{~mL})$ of the mixture was filtered using a short diatomaceous earth column $(\phi 10 \mathrm{~mm} \times 30 \mathrm{~mm})$, extracted with diethyl ether $(5.0 \mathrm{~mL})$, and then concentrated under reduced pressure.

\subsection{Microorganisms and Culture}

Conversions of the produced alcohols (Figure 1, 2a-h) was measured using a GLC with a DB-WAX capillary column $\left(100 \mathrm{kPa} \mathrm{He}, 110^{\circ} \mathrm{C}\right.$; 1a, $3.78 \mathrm{~min}$; 2a, $4.75 \mathrm{~min}$; 
1b, $4.73 \mathrm{~min}$; 2b, $5.92 \mathrm{~min} ; \mathbf{1 f}, 4.54 \mathrm{~min}$; $2 \mathbf{f}, 6.41 \mathrm{~min}$; $120^{\circ} \mathrm{C}$; 1c, $4.84 \mathrm{~min} ; 2 \mathrm{c}, 6.45 \mathrm{~min} ; 150^{\circ} \mathrm{C}, \mathbf{1 d}, 3.83 \mathrm{~min}$; 2d, $4.68 \mathrm{~min}$; 1e, $4.78 \mathrm{~min}$; $2 \mathbf{e}, 6.07 \mathrm{~min} ; 180^{\circ} \mathrm{C}$, 1g, 9.01 min; and $2 \mathrm{~g}, 12.08 \mathrm{~min})$ or a TC-1 capillary column (100 $\mathrm{kPa} \mathrm{He}, 140^{\circ} \mathrm{C}$; $\mathbf{1 h}, 10.02 \mathrm{~min}$; and $2 \mathbf{h}, 10.96 \mathrm{~min}$ ).

The enantiomeric excess (e.e.) of the product was measured using a GLC equipped with an optically active CP-Chirasil-DEX CB (2a-e, 2g-h) or Gamma DEX 225 capillary column (2f). The e.e. was calculated according to the following formula: e.e. $(\%)=\{(R-S) /(R+S)\} \times$ 100 . These $R$ and $S$ are the respective peak areas on GLC analyses. The absolute configurations of $\alpha$-hydroxy esters (2a-h) were identified by comparing their retention times from the GLC analyses with those of authentic samples [24].

\section{Results and Discussion}

\subsection{Screening of Marine-Derived Actinomycetes and Culture Media}

To search for a suitable medium for the liquid culture, the amount of wet cells obtained by cultivating of marine actinomycetes in various culture media was measured. The NBRC-recommended medium for 8 Micromonospora strains tested in this study was the 227 medium. Micromonospora strains cultured in the 227 medium, with the exception of NBRC 107094 and 107095, produced $5.0 \mathrm{~g}$ or less of the wet cells (Table 1). To improve the culture rate in the 227 medium, 3 new culture media (1076, 1076-25\%, and P-1076-25\% medium) containing marine water were tested for efficacy (1076-25\% and $\mathrm{P}-1076-25 \%$ media were newly designed in this study).

In the cultivation of these 8 strains using the 1076 medium including marine water ( $50 \%$ concentration), although over $6.0 \mathrm{~g}$ of wet cells of the NBRC107096 strain were obtained, $2.0 \mathrm{~g}$ or less of wet cells were obtain- ed for the NBRC107093, 107095, 107097 and 107098 strains. On the other hand, we obtained over $7.0 \mathrm{~g}$ of wetcells when the NBRC107096 and 107097 strains were cultured in the 1076-25\% medium (25\% marine water). Furthermore, to obtain more wet cells, Micromonospora strains were cultured in P-1076-25\% medium including polypepton ( $25 \%$ marine water); however, 5.0 $\mathrm{g}$ of wet cells was not obtained.

In a similar manner, a suitable medium for the liquid culture of 5 marine-derived Streptomyces strains was determined (Table 2). We found that the P-1076-25\% medium is most suitable for the liquid culture of the Streptomyces strains; in particular, the culture of Streptomyces sp. and $S$. tateyamensis yielded over $5.0 \mathrm{~g}$ of wet cells. In contrast, Streptomyces marinus did not show good growth in any culture medium (less than $1.0 \mathrm{~g}$ of wet cells was obtained).

Therefore, we investigated the possibility that $2 \mathrm{Mi}$ cromonospora strains (NBRC107096 and 107097) and 2 Streptomyces strains (Streptomyces tateyamensis NBRC105048 and Streptomyces sp. NBRC105896) can act as biocatalysts for the asymmetric reduction of carbonyl compounds.

\subsection{Reduction of $\alpha$-Keto Esters by Marine-Derived Micromonospora Strains}

Two Micromonospora strains (NBRC107096 and 107097) were tested for their ability to reduce $\alpha$-keto esters (Figure 1). The results of the $\alpha$-keto ester reductions are summarized in Table 3. We found that both Micromonospora strains reduced aliphatic and aromatic $\alpha$-keto esters (1a-h) to the corresponding alcohols (2a-h). The reduction of $\alpha$-keto esters by the NBRC107097 strain exhibited a higher conversion ratio than the reduction by the NBRC107096 strain; in particular, the NBRC107097

Table 1. The cultivation of marine-derived Micromonospora strains in various culture media.

\begin{tabular}{|c|c|c|c|c|c|}
\hline \multirow{2}{*}{ Strains } & \multirow{2}{*}{ NBRC } & 227 & 1076 & $1076-25 \%$ & P-1076-25\% \\
\hline & & Wet cells $(\mathrm{g})$ & Wet cells (g) & Wet cells $(\mathrm{g})$ & Wet cells $(\mathrm{g})$ \\
\hline Micromonospora sp. & 107092 & 3.6 & 3.0 & 5.4 & 0.5 \\
\hline Micromonospora sp. & 107093 & 4.1 & 1.0 & 5.4 & 2.5 \\
\hline Micromonospora sp. & 107095 & 5.4 & 0.6 & 5.8 & 3.3 \\
\hline Micromonospora sp. & 107096 & 1.6 & 6.6 & 7.4 & 1.8 \\
\hline Micromonospora sp. & 107097 & 4.7 & 1.6 & 8.0 & 1.2 \\
\hline Micromonospora sp. & 107098 & 0.1 & $<0.1$ & 1.6 & 2.5 \\
\hline Micromonospora sp. & 107099 & 1.0 & 2.6 & 3.9 & 1.0 \\
\hline
\end{tabular}


Table 2. The cultivation of marine-derived Streptomyces strains in various culture media.

\begin{tabular}{lccccc}
\hline \multirow{1}{*}{ Strains } & NBRC & 325 & 1076 & 1076-25\% & P-1076-25\% \\
\cline { 5 - 6 } & & Wet cells (g) & Wet cells (g) & Wet cells (g) & Wet cells (g) \\
\hline Streptomyces hygroscopicus subsp. hygroscopicus & 100580 & 0.1 & 1.8 & 1.9 & 2.1 \\
Streptomyces marinus & 105047 & 0.4 & 0.5 & 0.5 & 0.7 \\
Streptomyces tateyamensis & 105048 & 4.1 & 5.5 & 5.6 & 1.4 \\
Streptomyces haliclonae & 105049 & 0.8 & 1.1 & 2.5 & 1.9 \\
Streptomyces sp. & 105896 & 3.3 & 2.5 & 2.6 & 5.1 \\
\hline
\end{tabular}

Table 3. The reduction of $\alpha$-keto esters (1a-h) to the corresponding alcohols (2a-h) by 4 marine-derived actinomycetes.

\begin{tabular}{|c|c|c|c|c|c|c|c|c|c|c|c|c|}
\hline \multirow{3}{*}{ Product } & \multicolumn{3}{|c|}{ Micromonospora sp. ${ }^{1}$} & \multicolumn{3}{|c|}{ Micromonospora sp. ${ }^{1}$} & \multicolumn{3}{|c|}{ Streptomyces tateyamensis $^{2}$} & \multicolumn{3}{|c|}{ Streptomyces sp. $^{2}$} \\
\hline & \multicolumn{3}{|c|}{ NBRC107096 } & \multicolumn{3}{|c|}{ NBRC107097 } & \multicolumn{3}{|c|}{ NBRC105048 } & \multicolumn{3}{|c|}{ NBRC105896 } \\
\hline & $\begin{array}{l}\text { conv. } \\
(\%)^{3}\end{array}$ & $\begin{array}{l}\text { e.e. } \\
(\%)^{4}\end{array}$ & $(R / S)^{4}$ & $\begin{array}{l}\text { conv. } \\
(\%)^{3}\end{array}$ & $\begin{array}{l}\text { e.e. } \\
(\%)^{4}\end{array}$ & $(R / S)^{4}$ & $\begin{array}{l}\text { conv. } \\
(\%)^{3}\end{array}$ & $\begin{array}{l}\text { e.e. } \\
(\%)^{4}\end{array}$ & $(R / S)^{4}$ & $\begin{array}{l}\text { conv. } \\
(\%)^{3}\end{array}$ & $\begin{array}{l}\text { e.e. } \\
(\%)^{4}\end{array}$ & $(R / S)^{4}$ \\
\hline $2 a$ & $>99$ & 97 & $S$ & $>99$ & 92 & $S$ & 94 & $>99$ & $S$ & $>99$ & $>99$ & $S$ \\
\hline $2 \mathbf{b}$ & 89 & 73 & $S$ & $>99$ & 86 & $S$ & 97 & 72 & $R$ & $>99$ & $>99$ & $S$ \\
\hline 2c & $>99$ & 79 & $S$ & $>99$ & 84 & $S$ & $>99$ & $>99$ & $S$ & $>99$ & $>99$ & $S$ \\
\hline 2d & $>99$ & 80 & $S$ & $>99$ & 72 & $S$ & 97 & $>99$ & $S$ & $>99$ & 65 & $S$ \\
\hline $2 e$ & 71 & 75 & $S$ & 67 & 71 & $S$ & 15 & 76 & $R$ & 91 & 7 & $S$ \\
\hline $2 f$ & 93 & 13 & $S$ & $>99$ & 18 & $R$ & $>99$ & 28 & $R$ & $>99$ & 43 & $S$ \\
\hline $2 g$ & $>99$ & 70 & $S$ & 65 & 67 & $S$ & 19 & 6 & $S$ & $>99$ & 11 & $S$ \\
\hline $2 h$ & 73 & 18 & $R$ & $>99$ & 27 & $R$ & $>99$ & $>99$ & $S$ & $>99$ & 47 & $S$ \\
\hline
\end{tabular}

${ }^{1}$ Substrate $(0.15 \mathrm{mmol})$ and $0.85 \% \mathrm{NaCl}$ aq. $(20 \mathrm{ml})$ were added to the wet cells $(0.5 \mathrm{~g})$ cultured in $1076-25 \%$ medium, and the reaction mixture was incubated aerobically (reciprocating shaking at $\left.120 \mathrm{~min}^{-1}\right)$ at $25^{\circ} \mathrm{C}$ for $48 \mathrm{hrs}$. ${ }^{2}$ Substrate $(0.15 \mathrm{mmol})$ and $0.85 \% \mathrm{NaCl}$ aq. $(20 \mathrm{ml})$ were added to the wet cells $(0.5 \mathrm{~g})$ cultured in P-1076-25\% medium, and the reaction mixture was incubated aerobically (reciprocating shaking at 120 min ${ }^{-1}$ ) at $25^{\circ} \mathrm{C}$ for 48 hrs. ${ }^{3} \mathrm{Conversion}$ was measured by a GLC analysis. ${ }^{4}$ Enantiomeric excess (e.e.) and absolute configuration $(R / S)$ were determined by GLC analyses with optically active capillary columns.

strain had high reducing activity for substrates that had a short alkyl chain.

However, except for ethyl pyruvate (1a), the stereoselectivity of the produced alcohols was not high (13\% $80 \%$ e.e.). In the microbial reduction of carbonyl compounds using bakers' yeast or filamentous fungi (eukaryote), it is well known that the introduction of small organic molecules or metal ions will increase the stereoselectivity of the produced alcohols [25-27]. In contrast, in the reduction using actinomycetes (prokaryote), there are several reports that the addition of amino acids or sugars is effective in improving the conversion rate and stereoselectivity of products [12-14,23].

Therefore, the effect of additives on the reduction of keto esters using marine actinomycetes was investigated (see Table 4). Among various additives (e.g., sugars such as glucose, fructose, sucrose, and maltose or amino acids such as L-alanine, L-glycine, L-glutamate, and Laspartate), the introduction of L-glutamate or sucrose remarkably increased the conversion ratio of the reduc- tion. In particular, the reduction by the NBRC107096 strain in the presence of L-glutamate gave the corresponding $\alpha$-hydroxy ester with $>99 \%$ conversion ratio for all substrates. It appears that the increase in reduced nicotinamide-adenine dinucleotide (possibly NADPH) through the oxidative degradation of L-glutamate accelerates the reduction of $\alpha$-keto esters to the corresponding alcohols.

\subsection{Reduction of $\alpha$-Keto Esters by Marine-Derived Streptomyces Strains}

Two Streptomyces strains (NBRC105048 and 105896) were tested for their ability to reduce $\alpha$-keto esters. As shown in Table 3, we found that $\alpha$-keto esters (1a-h) were reduced by both Streptomyces strains to the corresponding hydroxy esters (2a-h). The NBRC105,896 strain had high reducing activity for $\alpha$-keto esters when compared with the NBRC105,048 strain and showed excellent conversion ratios ( $>99 \%$ in $\mathbf{2 a - d}$ and $\mathbf{2 f - h}$ ). Fur- 
Table 4. Effects of additives on the reduction of $\alpha$-keto esters (1a-h) with marine-derived Micromonospora strains ${ }^{1}$.

\begin{tabular}{|c|c|c|c|c|c|c|c|c|c|c|c|c|}
\hline \multirow{3}{*}{ Product } & \multicolumn{6}{|c|}{ Micromonospora sp. NBRC107096 } & \multicolumn{6}{|c|}{ Micromonospora sp. NBRC107097 } \\
\hline & \multicolumn{3}{|c|}{ L-glutamate } & \multicolumn{3}{|c|}{ Sucrose } & \multicolumn{3}{|c|}{ L-glutamate } & \multicolumn{3}{|c|}{ Sucrose } \\
\hline & $\begin{array}{c}\text { conv. } \\
(\%)^{2}\end{array}$ & $\begin{array}{l}\text { e.e. } \\
(\%)^{3}\end{array}$ & $(R / S)^{3}$ & $\begin{array}{l}\text { conv. } \\
(\%)^{2}\end{array}$ & $\begin{array}{l}\text { e.e. } \\
(\%)^{3}\end{array}$ & $(R / S)^{3}$ & $\begin{array}{c}\text { conv. } \\
(\%)^{2}\end{array}$ & $\begin{array}{l}\text { e.e. } \\
(\%)^{3}\end{array}$ & $(R / S)^{3}$ & $\begin{array}{c}\text { conv. } \\
(\%)^{2}\end{array}$ & $\begin{array}{l}\text { e.e. } \\
(\%)^{3}\end{array}$ & $(R / S)^{3}$ \\
\hline $2 a$ & $>99$ & 86 & $S$ & $>99$ & 89 & $S$ & $>99$ & $>99$ & $S$ & $>99$ & 91 & $S$ \\
\hline $2 \mathbf{b}$ & $>99$ & $>99$ & $S$ & $>99$ & 78 & $S$ & $>99$ & $>99$ & $S$ & $>99$ & 81 & $S$ \\
\hline 2c & $>99$ & 85 & $S$ & $>99$ & 87 & $S$ & $>99$ & 52 & $S$ & $>99$ & 87 & $S$ \\
\hline 2d & $>99$ & 62 & $S$ & 95 & 83 & $S$ & $>99$ & 76 & $S$ & $>99$ & 85 & $S$ \\
\hline $2 e$ & $>99$ & 27 & $S$ & 55 & 94 & $S$ & $>99$ & 76 & $S$ & 59 & 77 & $S$ \\
\hline $2 f$ & $>99$ & 22 & $S$ & $>99$ & 10 & $S$ & $>99$ & 26 & $S$ & $>99$ & 14 & $S$ \\
\hline $2 g$ & $>99$ & 78 & $S$ & 43 & 75 & $S$ & 99 & 74 & $S$ & 42 & 60 & $S$ \\
\hline $2 \mathrm{~h}$ & $>99$ & 28 & $R$ & 46 & 8 & $R$ & 99 & 8 & $R$ & 89 & 10 & $R$ \\
\hline
\end{tabular}

${ }^{1}$ Substrate $(0.15 \mathrm{mmol})$, additive $(5.0 \mathrm{mmol})$, and $0.85 \% \mathrm{NaCl}$ aq. $(20 \mathrm{ml})$ were added to the wet cells $(0.5 \mathrm{~g})$ cultured in $1076-25 \% \mathrm{medium}$, and the reaction mixture was incubated aerobically (reciprocating shaking at $120 \mathrm{~min}^{-1}$ ) at $25^{\circ} \mathrm{C}$ for $48 \mathrm{hrs} .{ }^{2}$ Conversion was measured by a GLC analysis. ${ }^{3}$ Enantiomeric excess (e.e.) and absolute configuration $(R / S)$ were determined by GLC analyses with optically active capillary columns.

Table 5. Effects of additives on the reduction of $\alpha$-keto esters (1a-h) with marine-derived Streptomyces strains ${ }^{1}$.

\begin{tabular}{|c|c|c|c|c|c|c|c|c|c|c|c|c|}
\hline \multirow{3}{*}{ Product } & \multicolumn{6}{|c|}{ Streptomyces tateyamensis NBRC105048 } & \multicolumn{6}{|c|}{ Streptomyces sp. NBRC105896 } \\
\hline & \multicolumn{3}{|c|}{ L-alanine } & \multicolumn{3}{|c|}{ Sucrose } & \multicolumn{3}{|c|}{ L-alanine } & \multicolumn{3}{|c|}{ Sucrose } \\
\hline & $\begin{array}{l}\text { conv. } \\
(\%)^{2}\end{array}$ & $\begin{array}{l}\text { e.e. } \\
(\%)^{3}\end{array}$ & $(R / S)^{3}$ & $\begin{array}{l}\text { conv. } \\
(\%)^{2}\end{array}$ & $\begin{array}{l}\text { e.e. } \\
(\%)^{3}\end{array}$ & $(R / S)^{3}$ & $\begin{array}{l}\text { conv. } \\
(\%)^{2}\end{array}$ & $\begin{array}{l}\text { e.e. } \\
(\%)^{3}\end{array}$ & $(R / S)^{3}$ & $\begin{array}{l}\text { conv. } \\
(\%)^{2}\end{array}$ & $\begin{array}{l}\text { e.e. } \\
(\%)^{3}\end{array}$ & $(R / S)^{3}$ \\
\hline 2a & $>99$ & $>99$ & $S$ & $>99$ & $>99$ & $S$ & $>99$ & 56 & $S$ & $>99$ & $>99$ & $S$ \\
\hline $2 \mathbf{b}$ & $>99$ & $>99$ & $S$ & $>99$ & 43 & $S$ & $>99$ & $>99$ & $S$ & $>99$ & $>99$ & $S$ \\
\hline 2c & $>99$ & $>99$ & $S$ & $>99$ & $>99$ & $S$ & $>99$ & 50 & $S$ & $>99$ & 56 & $S$ \\
\hline $2 d$ & $>99$ & $>99$ & $S$ & $>99$ & $>99$ & $S$ & 69 & 61 & $S$ & 73 & 61 & $S$ \\
\hline $2 e$ & 40 & $>99$ & $S$ & $>99$ & $>99$ & $S$ & 58 & 49 & $S$ & 60 & 48 & $S$ \\
\hline $2 f$ & $>99$ & $>99$ & $R$ & $>99$ & 43 & $R$ & 90 & 26 & $R$ & $>99$ & 33 & $R$ \\
\hline $2 g$ & 80 & 17 & $R$ & $>99$ & 75 & $R$ & 93 & 2 & $S$ & 59 & 18 & $R$ \\
\hline $2 h$ & 71 & 82 & $S$ & 48 & 32 & $S$ & 58 & 3 & $S$ & 59 & 43 & $S$ \\
\hline
\end{tabular}

${ }^{1}$ Substrate $(0.15 \mathrm{mmol})$, additive $(5.0 \mathrm{mmol})$, and $0.85 \% \mathrm{NaCl}$ aq. $(20 \mathrm{ml})$ were added to the wet cells $(0.5 \mathrm{~g})$ cultured in P-1076-25\% medium, and the reaction mixture was incubated aerobically (reciprocating shaking at $120 \mathrm{~min}^{-1}$ ) at $25^{\circ} \mathrm{C}$ for $48 \mathrm{hrs} .{ }^{2}$ Conversion was measured by a GLC analysis. ${ }^{3}$ Enantiomeric excess (e.e.) and absolute configuration $(R / S)$ were determined by GLC analyses with optically active capillary columns.

thermore, the reduction of 1a-c using the NBRC105,896 strain gave the corresponding $(S)$-hydroxy esters exclusively (>99\% e.e.).

An additive was introduced to the reaction mixture to improve the conversion ratio and stereoselectivity (see Table 5). As a result, the reduction of substrates using the NBRC105,048 strain in the presence of L-alanine or sucrose produced the corresponding alcohols with high conversion ratios (L-alanine, $>99 \%$, in 2a-d, 2f; sucrose, $>99 \%$, in 2a-g). In particular, the introduction of Lalanine improved not only the conversion rate but also the stereoselectivity of the products ( $>99 \%$ e.e. in $\mathbf{2 a - f})$. The effects of other additives (L-glycine, L-glutamate,
L-aspartate glucose, fructose, and maltose) were tested; however, the stereoselectivity of the produced alcohols did not increase (data not shown). In contrast, in the reduction by the NBRC105,896 strain, the conversion ratio was decreased by the introduction of the additive. This decrease in the conversion ratio was not expected.

\section{Conclusion}

Various $\alpha$-keto esters were converted to the corresponding $\alpha$-hydroxy esters by marine-derived actinomycetes. On the basis of the reduction conversion rates and the enantioselectivity of the products, we suggest that Strep- 
tomyces tateyamensis NBRC105048 and Micromonospora sp. NBRC107096 are potential biocatalysts for the stereoselective reduction of keto esters to obtain chiral hydroxy esters.

\section{REFERENCES}

[1] S. P. Stackebrandt, "Defining Taxonomic Ranks," In: M. Dworkin, Ed., The Prokaryotes: An Evolving Electronic Resource for the Microbiological Community, SpringerVerlag, New York, 2000.

[2] M. Ventura, C. Canchaya, A. Tauch, G. Chandra, G. F. Fitzgerald, K. F. Chater and D. van Sinderen, "Genomics of Actinobacteria: Tracing the Evolutionary History of an Ancient Phylum," Microbiology and Molecular Biology Reviews, Vol. 71, No. 3, 2007, pp. 495-548. doi:10.1128/MMBR.00005-07

[3] A. T. Bull, A. C. Ward and M. Goodfellow, "Search and Discovery Strategies for Biotechnology: The Paradigm Shift," Microbiology and Molecular Biology Reviews, Vol. 64, No. 3, 2000, pp. 573-606. doi:10.1128/MMBR.64.3.573-606.2000

[4] D. J. Newman and R. T. Hill, "New Drugs from Marine Microbes: The Tide Is Turning," Journal of Industrial Microbiology and Biotechnology, Vol. 33, No. 7, 2006, pp. 539-544. doi:10.1007/s10295-006-0115-2

[5] J. Solecka, J. Zajko, M. Postek and A. Rajnisz, "Biologically Active Secondary Metabolites from Actinomycetes," Central European Journal of Biology, Vol. 7, No. 3, 2012, pp. 373-390. doi:10.2478/s11535-012-0036-1

[6] J. Bérdy, "Bioactive Microbial Metabolites," Journal of Antibiotics, Vol. 58, No. 1, 2005, pp. 1-26. doi:10.1038/ja.2005.1

[7] W. R. Strohl, “Antimicrobials," In: A. T. Bull, Ed., Microbial Diversity and Bioprospecting, ASM Press, Washington, 2004, pp. 336-355.

[8] C. Olano, C. Méndez and J. A. Salas, "Antitumour Compounds from Marine Actinomycetes," Marine Drugs, Vol. 7, No. 2, 2009, pp. 210-248. doi:10.3390/md7020210

[9] J. Mann, "Natural Products as Immunosuppressive Agents," Natural Products Reports, Vol. 18, No. 4, 2001, pp. 417430.

[10] W. Pecznska-Czoch and M. Mordarski, "Actinomycete Enzymes," In: M. Goodfellow, S. T. Williams and M. Mordarski, Eds., Actinomycetes in Biotechnology, Academic Press, London, 1988, pp. 219-283. doi:10.1016/B978-0-12-289673-6.50011-7

[11] K. Ishihara, M. Nishitani, H. Yamaguchi, N. Nakajima, T. Ohshima and K. Nakamura, "Preparation of Optically Active $\alpha$-Hydroxy Esters: Stereoselective Reduction of $\alpha$ Keto Esters Using Thermophilic Actinomycetes," Journal of Fermentation and Bioengineering, Vol. 84, No. 3, 1997, pp. 268-270.

[12] K. Ishihara, H. Yamaguchi, H. Hamada, N. Nakajima and K. Nakamura, "Stereocontrolled Reduction of $\alpha$-Keto Esters with Thermophilic Actinomycete, Streptomyces Thermocyaneoviolaceus IFO14271," Journal of Molecular Catalysis, B: Enzymatic, Vol. 10, No. 2-6, 2000, pp. 429-
434. doi:10.1016/S1381-1177(03)00081-X

[13] K. Ishihara, H. Yamaguchi and N. Nakajima, "Stereoselective Reduction of Keto Esters: Thermophilic Bacteria and Microalgae as New Biocatalysts," Journal of Molecular Catalysis, B: Enzymatic, Vol. 23, No. 2-6, 2003, pp. 171-189.

[14] K. Ishihara, M. Nishimura, K. Nakashima, N. Machii, F. Miyake, M. Nishi, M. Yoshida, N. Masuoka and N. Nakajima, "Preparation of Chiral 2-Chloromandelamide: Stereoselective Reduction of an Aromatic $\alpha$-Keto Amide with Actinomycete," Biochemistry Insights, Vol. 3, 2010, pp. 19-24.

[15] S. T. Williams, M. Goodfellow and G. Alderson, "Genus Streptomyces Waksman and Henrich 1943, 339AL," In: S. T. Williams, M. E. Sharpe and J. G. Holt, Eds., Bergey's Manual of Systematic Bacteriology, Williams and Wilkins, Baltimore, 1989, pp. 2453-2492.

[16] J. W.-H. Li and J. C. Vederas, "Drug Discovery and Natural Products: End of an Era or an Endless Frontier?" Science, Vol. 325, No. 5937, 2009, pp. 161-165. doi:10.1126/science. 1168243

[17] W. Fenical and P. R. Jensen, "Developing a New Resource for Drug Discovery: Marine Actinomycete Bacteria," Nature Chemical Biology, Vol. 2, 2006, pp. 666-673. doi: doi:10.1038/nchembio841

[18] R. Solanki, M. Khanna and R. Lal, "Bioactive Compounds from Marine Actinomycetes," Indian Journal Microbiology, 2008, Vol. 48, No. 4, pp. 410-431. doi:10.1007/s12088-008-0052-Z

[19] S. Dharmaraj, "Marine Streptomyces as a Novel Source of Bioactive Substances," World Journal Microbiology and Biotechnology, Vol. 26, No. 12, 2010, pp. 2123-2139.

[20] S. T. Khan, H. Komaki, K. Motohashi, I. Kozone, A. Mukai, M. Takagi and K. Shin-Ya, "Streptomyces Associated with a Marine Sponge Haliclona sp.; Biosynthetic Genes for Secondary Metabolites and Products," Enviromental Microbiology, Vol. 13, No. 2, 2011, pp. 391-403.

[21] P. G. Williams, E. D. Miller, R. N. Asolkar, P. R. Jensen and W. Fenical, "Arenicolides A-C, 26-Membered Ring Macrolides from the Marine Actinomycete Salinispora arenicola," Journal of Organic Chemistry, Vol. 72, No. 14, 2007, pp. 5025-5034. doi:10.1021/jo061878x

[22] R. N. Asolkor, T. N. Kirkland, P. R. Jensen and W. Fenical, "Arenimycin, an Antibiotic Effective against Rifampin- and Methicillin-Resistant Staphylococcus aureus from the Marine Actinomycete Salinispora arenicola," Journal of Antibiotics, Vol. 63, No. 1, 2010, pp. 37-39. doi:10.1038/ja.2009.114

[23] K. Ishihara, H. Nagai, K. Takahashi, M. Nishiyama and N. Nakajima, "Stereoselective Reduction of $\alpha$-Keto Ester and $\alpha$-Keto Amide with Marine Actinomycetes, Salinispora Strains, as Novel Biocatalysts," Biochemistry Insights, Vol. 4, 2011, pp. 29-33. doi:10.4137/BCI.S7877

[24] K. Nakamura, K. Inoue, K. Ushio, S. Oka and A. Ohno, "Stereochemical Control on Yeast Reduction of $\alpha$-Keto Esters. Reduction by Immobilized Bakers' Yeast in Hexane," Journal of Organic Chemistry, Vol. 53, No. 11, 1998, pp. 2589-2593. doi:10.1021/jo00246a035 
[25] Y. Kawai, S. Kondo, M. Tsujimoto, K. Nakamura and A. Ohno, "Stereochemical Control in Microbial Reduction. XXIII. Thermal Treatment of Bakers' Yeast for Controlling the Stereoselectivity of Reductions," Bulletin of the Chemical Society of Japan, Vol. 67, No. 8, 1994, pp. 2244-2247. doi:10.1246/bcsj.67.2244

[26] Y. Kawai, K. Takanobe and A. Ohno, "Stereochemical Control in Microbial Reduction. XXV. Additives Controlling Diastereoselectivity in a Microbial Reduction of ethyl 2-Methyl-3-Oxobutanoate," Bulletin of Chemical Society of Japan, Vol. 68, No. 1, 1995, pp. 285-288. doi: $10.1246 /$ bcsj.68.285

[27] K. Nakamura, S. Kondo, Y. Kawai, K. Hida, K. Kitano and A. Ohno, "Enantio and Regioselective Reduction of $\alpha$-Diketones by Baker'S Yeast," Tetrahedron: Asymmetry, Vol. 7, No. 2, 1996, pp. 409-412. doi:10.1016/0957-4166(96)00020-1 